\title{
Degree of Concordance Between Calculated and Measured Low-Density Lipoprotein Cholesterol Methods
}

\author{
Sikandar Hayat Khan ${ }^{1}$, Farah Sobia ${ }^{2}$, Rahat Shahid ${ }^{2}$, Syed Ohen Raza Shah Bukhari', Syed Mohsin Manzoor ${ }^{4}$, \\ Roomana Anwar ${ }^{4}$ and Muhammad Tariq ${ }^{4}$
}

${ }^{1}$ Department of Pathology, Pakistan

${ }^{2}$ Department of Surgery, Pakistan

${ }^{3}$ Department of Medicine, Pakistan

${ }^{4}$ Medical Officer, Pakistan

Submission: July 10, 2020; Published: July 15, 2020

*Corresponding author: Sikandar Hayat Khan, Department of Pathology, PNS HAFEEZ Hospital, Pakistan

\section{Abstract}

Background: Low-density lipoprotein cholesterol (LDLc) remains a key lipid parameter and focus of clinical prevention targets for cardiovascular diseases. Although measured LDLc values are now available, many clinicians still rely on calculated method. Accordingly, several methods have evolved to overcome the shortcomings of previous models and improve risk prediction.

Objective: This study aims to compare the outcomes of various calculated and direct methods and to correlate biochemical risks with calculated and measured LDLc.

Design: Cross-sectional.

Place \& duration of study: Jan-17 to April-8 at Naval hospital.

Subjects and methods: The final analysis included 230 subjects with available mLDLc measurements. A paired t-test was used to compare measured and calculated methods developed by Friedewald et al [1], Anandaraja et al [2], Martin et al [3], Hattori et al [4], Chen et al [5], Vujovic et al [6], de Cordova et al [7], Ahmadi et al [8], Puavilai et al [9]. Subsequently, calculated parameters exhibiting non-significant associations were further evaluated using a Bland-Altman Plots.

Results: All calculated LDLc parameters except model of Ahmadi et al. exhibited moderate positive linear correlation with mLDLc. For the non-significant correlations of measured LDLc with Anandaraja-LDLc, Hatori-LDLc, and Cordova-LDLc, the level of agreement was demonstrated using Bland-Altman plots. Ahmadi et al method exhibited the strongest correlations with atherogenic small dense-LDLc, insulin resistance, and nephropathy.

Conclusion: Most calculated LDLc methods exhibited moderate correlations with measured methods; however, only results of Anandaraja \& Hatori et al. [2,4] and de Cordova et al, [7] closely resembled measured methods.

Keywords: LDL cholesterol; Friedewald formula; HbA1c

Abbreviations: FPG: Fasting Plasma Glucose; mLDLc: Measured LDLc; sdLDLc: Small Dense LDLc; HDLc: High-Density Lipoprotein Cholesterol; TG: Triglyceride; TC: Total Cholesterol; NCEP: National Cholesterol Education Program; OPDs: Outpatient Departments; UACR: Urine-AlbuminCreatinine Ratio; Cis: Confidence Intervals; VAP: Vertical Auto Profile

\section{Introduction}

In recent years, direct homogenous methods for measuring low-density lipoprotein cholesterol (LDLc) in clinical settings have been introduced. During the last decade, these techniques have improved in terms of both accuracy and precision [10], leading to their applications in large-scale clinical trials and reports of their clinical advantages [11]. At their core, these homogenous and direct LDLc methods aim to generate more reliable and clinically suitable data. However, the use of these methods is hindered by high costs, a reported lack of concordance between methods, and reproducibility issues $[12,13]$. 


\section{Current Research in Diabetes \& Obesity Journal}

It remains uncertain whether indirect calculation-based measures of LDLc would provide similarly reliable and acceptable clinical targets. However, the use of these measures into laboratory systems would likely be both cost- and labor-effective and highly precise. Following the introduction of an LDLc calculation-based methodology by Friedewald \& colleagues [1] (Friedewald-LDLc), multiple authors attempted to address the discrepancies identified in this approach. The original Friedewald equation incorporated the total cholesterol (TC), high-density lipoprotein cholesterol (HDLc) and triglyceride (TG) levels and divided the final variable by 2.2 to calculate the LDLc value (mmol/L) [1]. However, a review of the literature suggests that this equation exhibits positive bias at low TG values and would thus inflate the LDLc value even if the levels of both TG and TC were within normal ranges [14].

The National Cholesterol Education Program (NCEP) has defined strict targets for clinical laboratory measures, namely a total error of $<12 \%$ and precision and accuracy levels of $>96 \%$ [15]. Unfortunately, the data suggest that the currently available homogenous direct LDLc methods do not yet meet these performance characteristics [13,14]. Accordingly, biotechnological attempts to improve these homogenous methods have been accompanied by attempts to address the defects and shortcomings of calculated measures. For example, Martin et al. [3] demonstrated the superiority of an adjustable TG: very LDLc (VLDLc) ratio over the equation developed by Friedewald \& colleagues [1] Furthermore, de Cordova et al. recommended a simpler LDLc formula, namely LDLc $=3 / 4$ (TC - HDL) [8], while Chen et al. [5] calculated LDLc (mg/dl) as Non-HDL-C x 90\% - TG x $10 \%$ in an attempt to address the positive TG bias in patients with normal TC levels [9]. Similarly, Anadaraja \& Vujovic et al. [2,6] calculating LDLc $(\mathrm{mg} / \mathrm{dL})$ as $0.9 * \mathrm{TC}-0.9 * \mathrm{TG} / 5-28$ or $\mathrm{CLDLc}=\mathrm{TC}$ - HDL-C - (TG/6.58), respectively [2,6]. Ahmadi et al. [8] perceived that the Friedewald formula would overestimate the LDLc value in patients with lower serum TG levels and developed the formula of LDLc $(\mathrm{mmol} / \mathrm{L})=\mathrm{TC} / 1.19$ +Triglycerides/0.81 - HDLc/1.1 - 0.98 [8]. Still other researchers have similarly attempted to address the limitations of existing LDLc calculation methods [4,9].

The above review suggests considerable variance among the results of LDLc calculation-based methods used around the world. These discrepancies have shown confusion, as LDLc is defined as the lipoprotein fraction isolated by ultracentrifugation with a density of 1.019-1.063 g/ml [16]. Moreover, evidence suggests that LDLc can be further fractionated into more (e.g., small dense LDLc [sdLDLc]) and less atherogenic fractions (e.g., large buoyant LDLc [lbLDLc]). This characteristic has evoked questions regarding which of the available equations could best identify with atherogenic lipidemia and conventional biochemical risks [17]. In this study, we aimed to compare and correlate the LDLc fractions calculated using various methods with the measured homogenous LDLc results while considering the aforementioned evidence and assuming the homogenous methods depict the actual CVD risk. This study also aimed to correlate the homogenous and calculated values with traditional biochemical risk factors to determine the optimal method for risk prediction.

\section{Methods}

This cross-sectional study was conducted in the Departments of Pathology and Medicine of PNS HAFEEZ Hospital from January 2017 to April 2018. Formal approval for this study was sought from the ethical review board of this hospital. Patients who reported for the evaluation of plasma glucose or lipid profiles while in a medical fasting state in various Out Patient Departments (OPDs) were invited to participate. All potential subjects were briefed about the study, the use of their data, and the probable side effects of phlebotomy, and those who agreed to participate were asked to provide a signed consent form and their clinical details and history as per the study questionnaire. Subsequently, the participants underwent a baseline clinical examination, including the collection of blood pressure and anthropometric data. At this stage, the primary exclusion criteria were a chronic disease (e.g., diabetes, hypertension, or ischemic heart disease), pregnancy, inappropriate medical fasting, or the use of medication for chronic or acute medical disorders. The initial dataset included 232 subjects; however, two samples could not be analyzed during the study due to technical mistakes.

From each subject, a 10-ml sample of blood was collected and divided into tubes containing sodium fluoride, EDTA, or no additives. The total cholesterol, triglycerides, and glucose levels were analyzed using the CHOD-PAP, GPO-PAP, and GODPAP methods, respectively. The LDLc and HDLc levels were measured via cholesterol esterase methodology using an ADVIA 1800 clinical chemistry system. Glycated hemoglobin (HbA1c) was measured using ion-exchange resin chromatography by $3^{\mathrm{RD}}$ generation ELISA on Elisys Uno instrument (HUMAN). Spot measures of the urine-albumin-creatinine ratio (UACR) were performed in 174 subjects via immuno-turbidimetry using the ADVIA 1800 system. Serum insulin levels were analyzed via a chemiluminescence method using the Immulite ${ }^{\circledR} 1000$ device. The Homeostasis Model Assessment for insulin resistance (HOMA-IR) equation was calculated according to Mathew et al. [17] The sdLDLc level was calculated as described by Srisawasdi et al. [18]. The various equations used to calculate LDLc are listed in Table 1. The hospital lab daily performs internal quality control AS PER Westgard's rules for accepting or rejecting batches along with participates regularly in National External Quality Assurance Program of Pakistan (NEQAPP). Every attempt is made to keep the analytical imprecision and accuracy targets within the NCEP defined parameters. Errors, if any are addressed till rectification as per Westgard's methodology. 


\section{Current Research in Diabetes \& Obesity Journal}

Table 1: Various LDLc calculation methods and respective equations.

\begin{tabular}{|c|c|c|c|}
\hline Ser & Calculated LDLc Version & Formula & Reference \\
\hline 1 & Directly measured LDLc & - & Cholesterol esterase methodology \\
\hline 2 & Frid-LDLc ${ }^{2}$ & $\operatorname{cLDLc}=\mathrm{TC}^{* *}-\left[\mathrm{HDLc}-\mathrm{TG}^{*} / 2.2\right]$ & Friedewald et al. [1] \\
\hline 3 & Anan-LDLc ${ }^{3}$ & $\operatorname{cLDLc}(\mathrm{mg} / \mathrm{dL})=0.9 \times \mathrm{TC}-0.9 \times \mathrm{TG} / 5-28$ & Anandaraja et al. [2] \\
\hline 4 & Mart-LDLc ${ }^{4}$ & $\begin{array}{l}\text { As per calculator: http://www.ldlcalculator. } \\
\text { com/ }\end{array}$ & Martin et al. [3] \\
\hline 5 & Hatt-LDLc ${ }^{5}$ & $\begin{array}{c}\text { LDL-C }=(0.94 \times \mathrm{TC})-(0.94 \times \mathrm{HDL}-\mathrm{C})-(0.19 \times \\
\mathrm{TG})\end{array}$ & Hattori et al. [4] \\
\hline 6 & Chen-LDLc ${ }^{6}$ & $\operatorname{cLDLc}=($ Non $-H D L c) \times 0.9-(T G \times 0.1)$ & Chen et al. [5] \\
\hline 7 & Vujo-LDLc ${ }^{7}$ & $\mathrm{cLDLc}=\mathrm{TC}-\mathrm{HDL}-\mathrm{C}-(\mathrm{TG} / 6.58)$ & Vujovic et al. [6] \\
\hline 8 & Cord-LDLc $^{8}$ & $\mathrm{cLDLc}=3 / 4(\mathrm{TC}-\mathrm{HDL})$ & de Cordova et al. [7] \\
\hline 9 & Ahma-LDLc ${ }^{9}$ & $\begin{array}{c}\operatorname{cLDLc}(\mathrm{mmol} / \mathrm{L})=\mathrm{TC} / 1.19+\mathrm{TG} / 0.81- \\
\mathrm{HDLc} / 1.1-0.98\end{array}$ & Ahmadi et al. [8] \\
\hline 10 & Puav-LDLc ${ }^{10}$ & $\mathrm{cLDLc}=\mathrm{TC}-\mathrm{HDL}-1 / 6 \mathrm{TG}$ & Puavilai et al. [9] \\
\hline
\end{tabular}

${ }^{1}$ Directly measured LDLc, ${ }^{2}$ Friedwald-LDLc, ${ }^{3}$ Anandaraja-LDLc, ${ }^{4}$ Martin-LDLc, ${ }^{5}$ Hatori-LDLc, ${ }^{6}$ Chen-LDLc, ${ }^{7}$ Vujovic-LDLc, ${ }^{8}$ De Cordova-LDLc, ${ }^{9}$ Ahmadi-LDLC, ${ }^{10}$ Puavilai- LDLC, ${ }^{*}$ TC: Total cholesterol; ${ }^{* *}$ TG: Triglycerides

\section{Statistical analysis}

Data were initially entered into Microsoft Excel spreadsheets (version 2007). All abovementioned calculated LDLc values and conversions from units of $\mathrm{mg} / \mathrm{dl}$ were performed using Excel and subsequently transferred to SPSS (version 15) for the statistical analysis. Descriptive statistics were calculated for age and sex using SPSS analyze function. A Pearson's correlation analysis was used to calculate the correlations of measured LDLc values with all calculated LDLc values and with biochemical parameters such as the HOMA-IR (insulin resistance), HOMA\%B (insulin sensitivity surrogate), UACR, fasting plasma glucose, HbA1c, and sdLDLc. Differences between the measured and various calculated LDLc levels were calculated using paired sample t-test. Subsequently, non-significant associations were further evaluated using BlandAltman plots with 95\% confidence intervals (CIs). Finally, a Pearson's correlation was used to determine the correlation coefficients for the relationships of all LDLc measures with the aforementioned biochemical risk indicators. A p-value of $<0.05$ was considered as statistically significant.

Results

Our dataset included 122 female and 108 male subjects with a mean (+ SD) age of $46.50( \pm 11.91)$ years. The mean body mass index and waist-to-hip ratio were $27.17( \pm 5.22)$ and $0.93( \pm 0.082)$, respectively. Table 2 presents the results of a Pearson correlation analysis between various calculated and measured LDLc values. Notably, a paired sample t-test yielded non-significant differences of the measured LDLc with the calculations obtained using the Anandaraja-LDLc, Hatori-LDLc, and De Cordova-LDLc equations (Table 3). Accordingly, we developed Bland-Altman plots for those LDLc parameters which matched measured LDLc as shown in Figures 1-3.

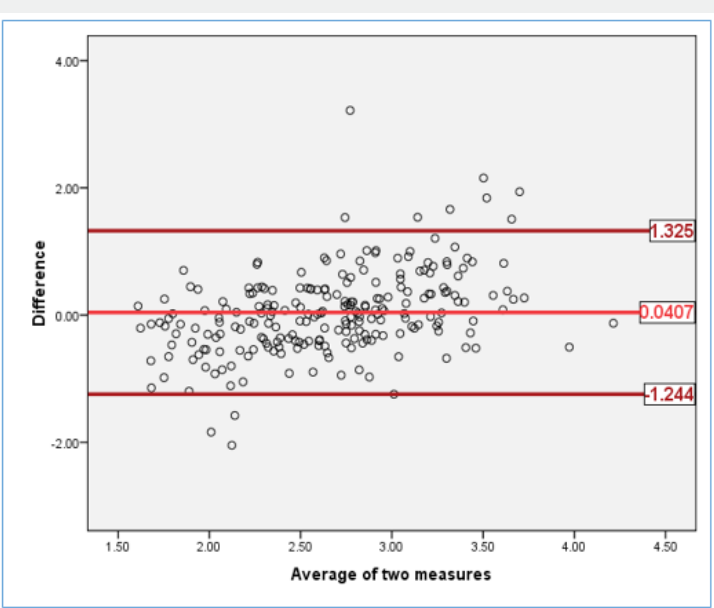

Figure 1: Bland-Altman plot (with 95\% confidence intervals) of the limits of agreement between the measured LDLc values and those calculated according to Anandaraja et al. [2]. 


\section{Current Research in Diabetes \& Obesity Journal}

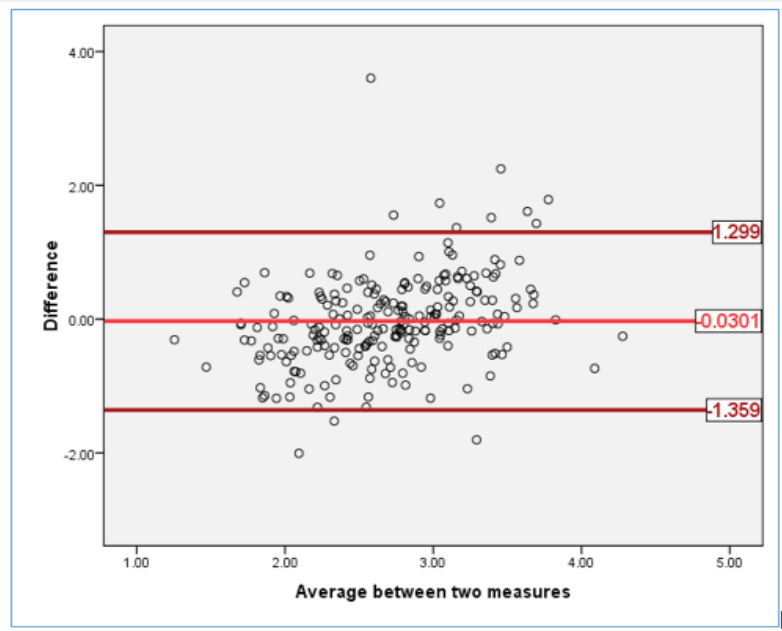

Figure 2: Bland-Altman plot (with 95\% confidence intervals) of the limits of agreement between the measured LDLc values and those calculated according to Hatori et al. [4].

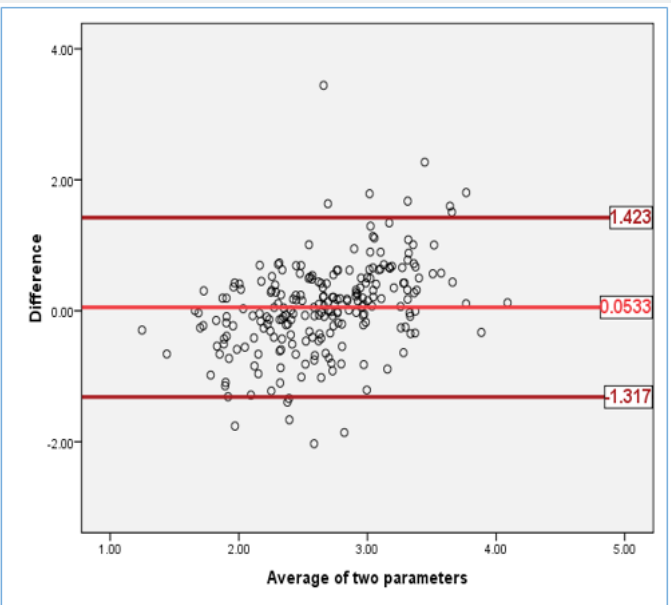

Figure 3: Bland-Altman plot (with 95\% confidence intervals) of the limits of agreement between the measured LDLc values and those calculated according to de Cordova et al [7].

Table 2: Results of a Pearson's correlation analysis of various calculated and measured LDLc values.

\begin{tabular}{|c|c|c|c|}
\hline Ser & LDLc Calculation Method & Parameter & mLDLc1 (mmol/L) \\
\hline \multirow{3}{*}{1} & \multirow{3}{*}{ Frid-LDLc ${ }^{2}(\mathrm{mmol} / \mathrm{L})$} & Pearson Correlation & $0.468^{* *}$ \\
\hline & & Sig. (two-tailed) & $<0.001$ \\
\hline & & $\mathrm{N}$ & 230 \\
\hline \multirow{3}{*}{2} & \multirow{3}{*}{ Anan-LDLc ${ }^{3}(\mathrm{mmol} / \mathrm{L})$} & Pearson Correlation & $0.469^{* *}$ \\
\hline & & Sig. (two-tailed) & $<0.001$ \\
\hline & & $\mathrm{N}$ & 230 \\
\hline \multirow{3}{*}{3} & \multirow{3}{*}{ Mart-LDLc ${ }^{4}(\mathrm{mmol} / \mathrm{L})$} & Pearson Correlation & $0.434^{* *}$ \\
\hline & & Sig. (two-tailed) & $<0.001$ \\
\hline & & $\mathrm{N}$ & 230 \\
\hline \multirow{3}{*}{4} & \multirow{3}{*}{ Hatt-LDLc ${ }^{5}(\mathrm{mmol} / \mathrm{L})$} & Pearson Correlation & $0.445^{* *}$ \\
\hline & & Sig. (two-tailed) & $<0.001$ \\
\hline & & $\mathrm{N}$ & 230 \\
\hline
\end{tabular}




\section{Current Research in Diabetes \& Obesity Journal}

\begin{tabular}{|c|c|c|c|}
\hline \multirow{3}{*}{5} & \multirow{3}{*}{ Chen-LDLc ${ }^{6}(\mathrm{mmol} / \mathrm{L})$} & Pearson Correlation & $0.442^{* *}$ \\
\hline & & Sig. (two-tailed) & $<0.001$ \\
\hline & & $\mathrm{N}$ & 230 \\
\hline \multirow{3}{*}{6} & \multirow{3}{*}{ Vujo-LDLc ${ }^{7}(\mathrm{mmol} / \mathrm{L})$} & Pearson Correlation & $0.456^{* *}$ \\
\hline & & Sig. (two-tailed) & $<0.001$ \\
\hline & & $\mathrm{N}$ & 230 \\
\hline \multirow{3}{*}{7} & \multirow{3}{*}{ Cord-LDLc ${ }^{8}(\mathrm{mmol} / \mathrm{L})$} & Pearson Correlation & $0.380^{* *}$ \\
\hline & & Sig. (two-tailed) & $<0.001$ \\
\hline & & $\mathrm{N}$ & 230 \\
\hline \multirow{3}{*}{8} & \multirow{3}{*}{ Ahma-LDLc ${ }^{9}(\mathrm{mmol} / \mathrm{L})$} & Pearson Correlation & $0.140^{*}$ \\
\hline & & Sig. (two-tailed) & $<0.001$ \\
\hline & & $\mathrm{N}$ & 230 \\
\hline \multirow{3}{*}{9} & \multirow{3}{*}{ Puav-LDLc ${ }^{10}(\mathrm{mmol} / \mathrm{L})$} & Pearson Correlation & $0.462^{* *}$ \\
\hline & & Sig. (two-tailed) & $<0.001$ \\
\hline & & $\mathrm{N}$ & 230 \\
\hline
\end{tabular}

${ }^{1}$ Directly measured LDLc, ${ }^{2}$ Friedwald-LDLc, ${ }^{3}$ Anandaraja-LDLc, ${ }^{4}$ Martin-LDLc, ${ }^{5}$ Hatori-LDLc, ${ }^{6}$ Chen-LDLc, ${ }^{7}$ Vujovic-LDLc, ${ }^{8}$ De Cordova-LDLc, ${ }^{9}$ Ahmadi-LDLc, ${ }^{10}$ Puavilai- LDLC

Table 3: Differences between measured and various calculated LDLc values $(n=230)$.

\begin{tabular}{|c|c|c|c|c|}
\hline LDLc Measure & Mean & Standard Deviation & Standard Error of the Mean & (Two-tailed) p-Value* \\
\hline $\operatorname{mLDLc}^{1}(\mathrm{mmol} / \mathrm{L})$ & 2.68 & 0.72 & 0.048 & \\
\hline Frid-LDLc ${ }^{2}(\mathrm{mmol} / \mathrm{L})$ & 2.78 & 0.54 & 0.035 & 0.037 \\
\hline Anan-LDLc ${ }^{3}(\mathrm{mmol} / \mathrm{L})$ & 2.64 & 0.49 & 0.032 & 0.348 \\
\hline Mart-LDLc ${ }^{4}(\mathrm{mmol} / \mathrm{L})$ & 2.86 & 0.53 & 0.035 & $<0.001$ \\
\hline Hatt-LDLc ${ }^{5}(\mathrm{mmol} / \mathrm{L})$ & 2.71 & 0.52 & 0.034 & 0.501 \\
\hline Chen-LDLc $^{6}(\mathrm{mmol} / \mathrm{L})$ & 2.79 & 0.5 & 0.033 & 0.019 \\
\hline Vujo-LDLc ${ }^{7}(\mathrm{mmol} / \mathrm{L})$ & 2.97 & 0.55 & 0.036 & $<0.001$ \\
\hline Cord-LDLc $^{8}(\mathrm{mmol} / \mathrm{L})$ & 2.63 & 0.48 & 0.031 & 0.249 \\
\hline Ahma-LDLc ${ }^{9}(\mathrm{mmol} / \mathrm{L})$ & 3.83 & 1.27 & 0.834 & $<0.001$ \\
\hline Puav-LDLc ${ }^{10}(\mathrm{mmol} / \mathrm{L})$ & 2.89 & 0.54 & 0.036 & $<0.001$ \\
\hline
\end{tabular}

${ }^{1}$ Directly measured LDLc, ${ }^{2}$ Friedwald-LDLc, ${ }^{3}$ Anandaraja-LDLc, ${ }^{4}$ Martin-LDLc, ${ }^{5}$ Hatori-LDLc, ${ }^{6}$ Chen-LDLc, ${ }^{7}$ Vujovic-LDLc, ${ }^{8}$ De Cordova-LDLc, ${ }^{9}$ Ahmadi-LDLc, ${ }^{10}$ Puavilai- LDLC

${ }^{*}$ A paired t-test was used to compare all calculated and measured LDLc values.

Table 4 lists the correlations of the calculated and measured LDLc values with biochemical risk factors such as nephropathy, insulin resistance and sensitivity, and various diabetic parameters. A Pearson's correlation analysis of risk yielded the highest positive linear correlation coefficient $(r)$ of $0.778(p<0.001)$ for the association between mLDLc and risk, followed by the formulas suggested by Ahmadi et al, [8] $0.662(\mathrm{p}<0.001)$ and de Cordova et al, [7] ( $r=0.470, p<0.001)$. The other calculated values exhibited modest correlations with mLDLc, whereas the value calculated using the Friedewald equation yielded the weakest correlation of 0.198 ( $p=0.003$ ). Our results further identified the LDLc value calculated according to Ahmadi et al, [8] as the most strongly correlated with the metabolic parameters of nephropathy ( $\mathrm{r}=$ $0.139, \mathrm{p}=0.067)$ and insulin resistance $(\mathrm{r}=0.259, \mathrm{p}<0.001)$. None of the other calculated values or the measured LDLc value correlated significantly metabolic parameters. 


\section{Current Research in Diabetes \& Obesity Journal}

Table 4: Correlations of various biochemical CVD risks with calculated and measured LDLc values.

\begin{tabular}{|c|c|c|c|c|c|c|c|c|c|}
\hline & & $\begin{array}{c}\text { FPG } \\
(\mathrm{mmol} / \mathrm{L})\end{array}$ & $\begin{array}{c}\text { sdLDLc } \\
(\mathrm{mmol} / \mathrm{L})\end{array}$ & $\begin{array}{c}\text { VLDLC } \\
(\mathrm{mmol} / \mathrm{L})\end{array}$ & $\begin{array}{c}\text { HbA1c } \\
(\%)\end{array}$ & $\begin{array}{l}\text { Insulin } \\
\text { (mIU/L) }\end{array}$ & HOMA-IR & $\begin{array}{c}\text { HOMA- } \\
\% B\end{array}$ & $\begin{array}{c}\text { UACR } \\
\text { (mg/g) }\end{array}$ \\
\hline \multirow{3}{*}{$\begin{array}{c}\mathrm{mLDLc}^{1} \\
(\mathrm{mmol} / \mathrm{L})\end{array}$} & Pearson Correlation & -0.025 & $0.778^{* *}$ & -0.029 & -0.011 & 0.001 & -0.035 & 0.022 & 0.098 \\
\hline & Sig. (two-tailed) & 0.711 & $<0.001$ & 0.666 & 0.864 & 0.989 & 0.598 & 0.743 & 0.197 \\
\hline & $\mathrm{N}$ & 230 & 230 & 230 & 226 & 227 & 227 & 227 & 173 \\
\hline \multirow{3}{*}{$\begin{array}{c}\text { HDLc } \\
(\mathrm{mmol} / \mathrm{L})\end{array}$} & Pearson Correlation & -0.099 & $-0.132^{*}$ & $-.290 * *$ & 0.033 & -0.069 & -0.086 & -0.03 & -0.079 \\
\hline & Sig. (two-tailed) & 0.134 & 0.046 & $<0.001$ & 0.626 & 0.302 & 0.197 & 0.654 & 0.304 \\
\hline & $\mathrm{N}$ & 229 & 229 & 229 & 226 & 226 & 226 & 226 & 173 \\
\hline \multirow{3}{*}{$\begin{array}{l}\text { Frid-LD- } \\
\mathrm{Lc}^{2} \\
(\mathrm{mmol} / \mathrm{L})\end{array}$} & Pearson Correlation & -0.092 & $0.198 * *$ & 0.009 & $-0.139 *$ & 0.024 & -0.033 & 0.041 & 0.089 \\
\hline & Sig. (two-tailed) & 0.163 & 0.003 & 0.896 & 0.036 & 0.716 & 0.616 & 0.536 & 0.242 \\
\hline & $\mathrm{N}$ & 230 & 230 & 230 & 226 & 227 & 227 & 227 & 173 \\
\hline \multirow{3}{*}{$\begin{array}{l}\text { Ana-LDLc }{ }^{3} \\
(\mathrm{mmol} / \mathrm{L})\end{array}$} & Pearson Correlation & $-0.152 *$ & $0.149 *$ & -0.121 & -0.121 & -0.006 & -0.074 & 0.032 & 0.047 \\
\hline & Sig. (two-tailed) & 0.021 & 0.024 & 0.067 & 0.07 & 0.927 & 0.264 & 0.634 & 0.537 \\
\hline & $\mathrm{N}$ & 230 & 230 & 230 & 226 & 227 & 227 & 227 & 173 \\
\hline \multirow{3}{*}{$\begin{array}{l}\text { Mart-LD- } \\
\mathrm{Lc}^{4} \\
(\mathrm{mmol} / \mathrm{L})\end{array}$} & Pearson Correlation & -0.013 & $0.338^{* *}$ & $0.277^{* *}$ & -0.104 & 0.068 & 0.05 & 0.042 & 0.115 \\
\hline & Sig. (two-tailed) & 0.843 & $<0.001$ & $<0.001$ & 0.121 & 0.31 & 0.456 & 0.534 & 0.132 \\
\hline & $\mathrm{N}$ & 230 & 230 & 230 & 226 & 227 & 227 & 227 & 173 \\
\hline \multirow{3}{*}{$\begin{array}{c}\text { Hatt-LD- } \\
\text { Lc }^{5} \\
(\mathrm{mmol} / \mathrm{L})\end{array}$} & Pearson Correlation & -0.021 & $0.333^{* *}$ & $0.255^{* *}$ & -0.108 & 0.065 & 0.039 & 0.045 & 0.114 \\
\hline & Sig. (two-tailed) & 0.757 & $<0.001$ & $<0.001$ & 0.107 & 0.33 & 0.559 & 0.498 & 0.134 \\
\hline & $\mathrm{N}$ & 230 & 230 & 230 & 226 & 227 & 227 & 227 & 173 \\
\hline \multirow{3}{*}{$\begin{array}{l}\text { Chen-LD- } \\
\text { Lc }^{6} \\
(\mathrm{mmol} / \mathrm{L})\end{array}$} & Pearson Correlation & -0.015 & $0.343^{* *}$ & $.275^{* *}$ & -0.105 & 0.068 & 0.045 & 0.045 & 0.116 \\
\hline & Sig. (two-tailed) & 0.827 & $<0.001$ & $<0.001$ & 0.117 & 0.306 & 0.501 & 0.496 & 0.128 \\
\hline & $\mathrm{N}$ & 230 & 230 & 230 & 226 & 227 & 227 & 227 & 173 \\
\hline \multirow{3}{*}{$\begin{array}{l}\text { Vuj-LDLc }{ }^{7} \\
(\mathrm{mmol} / \mathrm{L})\end{array}$} & Pearson Correlation & -0.045 & $0.289 * *$ & $0.173^{* *}$ & -0.119 & 0.052 & 0.015 & 0.044 & 0.107 \\
\hline & Sig. (two-tailed) & 0.497 & $<0.001$ & 0.008 & 0.074 & 0.44 & 0.827 & 0.508 & 0.162 \\
\hline & $\mathrm{N}$ & 230 & 230 & 230 & 226 & 227 & 227 & 227 & 173 \\
\hline \multirow{3}{*}{$\begin{array}{l}\text { Cor-LDLc }^{8} \\
(\mathrm{mmol} / \mathrm{L})\end{array}$} & Pearson Correlation & 0.07 & $0.470^{* *}$ & $.537^{* *}$ & -0.06 & 0.11 & 0.125 & 0.046 & 0.136 \\
\hline & Sig. (two-tailed) & 0.294 & $<0.001$ & $<0.001$ & 0.37 & 0.099 & 0.059 & 0.488 & 0.073 \\
\hline & $\mathrm{N}$ & 230 & 230 & 230 & 226 & 227 & 227 & 227 & 173 \\
\hline \multirow{3}{*}{$\begin{array}{c}\text { Ah- } \\
\text { ma-LDLc } \\
(\mathrm{mmol} / \mathrm{L})\end{array}$} & Pearson Correlation & $.227^{* *}$ & $0.602^{* *}$ & $0.933^{* *}$ & 0.048 & $0.166^{*}$ & $0.259^{* *}$ & 0.035 & 0.139 \\
\hline & Sig. (two-tailed) & $<0.001$ & $<0.001$ & $<0.001$ & 0.475 & 0.012 & $<0.001$ & 0.603 & 0.067 \\
\hline & $\mathrm{N}$ & 230 & 230 & 230 & 226 & 227 & 227 & 227 & 173 \\
\hline \multirow{3}{*}{$\begin{array}{l}\text { Pua-LD- } \\
\text { Lc }^{10} \\
\text { (mmol/L) }\end{array}$} & Pearson Correlation & -0.063 & $.255^{* *}$ & 0.11 & -0.127 & 0.041 & -0.004 & 0.043 & 0.1 \\
\hline & Sig. (two-tailed) & 0.338 & $<0.001$ & 0.097 & 0.056 & 0.538 & 0.952 & 0.517 & 0.189 \\
\hline & $\mathrm{N}$ & 230 & 230 & 230 & 226 & 227 & 227 & 227 & 173 \\
\hline
\end{tabular}

${ }^{1}$ Directly measured LDLc, ${ }^{2}$ Friedwald-LDLc, ${ }^{3}$ Anandaraja-LDLc, ${ }^{4}$ Martin-LDLc, ${ }^{5}$ Hatori-LDLc, ${ }^{6}$ Chen-LDLc, ${ }^{7}$ Vujovic-LDLc, ${ }^{8}$ De Cordova-LDLc, ${ }^{9}$ Ahmadi-LDLc, ${ }^{10}$ Puavilai- LDLC

\section{Discussion}

Our study identified moderate correlations between directly measured LDLc and most available equations. Interestingly, the calculated LDLc according to Ahmedi et al, [8] correlated very weakly with the measured LDLc; however, these calculated values exhibited the strongest correlations with atherogenic lipid levels (e.g., sdLDLc), insulin resistance, and nephropathy, whereas no other calculated value correlated strongly with biochemical risk factors. Furthermore, the Anandaraja-LDLc, Hatori-LDLc, and Cordova-LDLc equations were not associated with measured LDLc.

The "LDLc concept", which was used to define the current primary and second treatment targets, represents a progression from various discoveries in the rapidly evolving field of "lipidology." 
However, the existing literature suggests that although LDLc has some utility, it is not a good biomarker of CVD. Ide et al. observed that in patients with CVD, the LDL concentrations remained stable even after the initiation of a polyunsaturated diet. However, these authors observed an increase in large LDL particles and concomitant decrease in sdLDL particles consequent to this dietary intervention [19]. The potential lack of association between an elevated LDLc level and the atherogenicity is consistent with the possibility that a normal LDLc level might mask an elevated level of sdLDLc, a CVD risk factor [20]. Therefore, we might attribute the weak correlations between LDL measures and biochemical risk biomarkers to the stronger association of the CVD risk with the level of sdLDL particles, rather than the overall LDLc concentration $[21,22]$.

It remains uncertain why only the LDLc value calculated according to Ahmadi et al, [8] exhibited strong correlations with atherogenic dyslipidemia, insulin resistance, and a marker of surrogate nephropathy, even in the presence of normolipidemia. This finding might be attributable to the well-known Asian "Atherogenic lipid triad [23]." Given its strong correlation with sdLDLc, this equation appears to be more suitable for the individuals suspected to have atherogenic dyslipidemia, particularly those in the Asian population. Consistent with our findings Goel et al, [24] demonstrated that Indian patients with coronary artery disease had higher levels of sdLDLc despite normal levels of LDLc, suggesting that the former is a more effective parameter when assessing CVD. We further observed that the LDLc value calculated according to Anandaraja et al, [2] exhibited a moderate and non-significant correlation with the measured value. However, the exclusion of HDLc from this equation is likely responsible for the lack of correlations between the calculated value and biochemical CVD risks [10].

Our observation of the variability and minimal degree of agreement between most calculated LDLc values with mLDLc and the inability of these values to indicate insulin resistance, atherogenic dyslipidemia, and nephropathy suggest the need for a different diagnostic approach towards lipid disorders. Kinetic studies have demonstrated that the regulation of lipids and lipoproteins in the body is a dynamic process wherein cholesterol, fatty acids, and apolipoproteins are exchanged and thus alter the shapes, sizes, densities, and characteristics of lipoproteins $[19,25,26]$. Given that these changes occur rapidly within the plasma, our broader biotechnological understanding of the interactions of lipids and lipoproteins leads us to suggest that the analyses of LDLc and HDLc sub-fractions may provide a better indicator of the CVD risk. Consistent with our suggestion, Collins et al. identified multiple differences in proteins within LDLc using liquid chromatography-tandem mass spectrometry [27]. For example, the vertical auto profile (VAP) clearly demonstrates a shift from the conventional lipid profile to an evaluation of smaller sub-fractions within the lipid profile, thus enabling a better evaluation of the CVD risk that accounts for the residual risk and atherogenic dyslipidemias [28]. However, in our Pakistani cohort, we found that the values calculated according to Ahmadi et al. exhibited excellent correlations with multiple CVD risks.

Our study findings have significant clinical implications. First, although this study aimed to compare the various published formulas and thus identify a method superior to that of Friedewald et al, [1] we found that the values yielded by most equations did not correlate with the measured LDLc values. Moreover, we highlighted poor correlations of biochemical risk factors with the measured and all calculated LDLc values except the value determined according to Ahmadi et al, [8] suggesting that this equation may actually be useful in a Pakistani population. More significantly, our study highlighted the importance of clarifying the smaller LDLc fractions and improving the related lab tests used for diagnosis and monitoring.

Still, we must highlight certain limitations of our study. First, the study was conducted in an urbanized Pakistani population, which has been reported to exhibit a higher degree of atherogenic dyslipidemia [23, 24]. Accordingly, our findings must be validated in other regions. Second, our study design was cross-sectional and conducted using data collected in clinical settings. Therefore, epidemiological studies are needed to confirm our findings.

\section{Conclusion}

Most of the LDLc values calculated existing equations exhibited moderate correlations with the measured LDLc values. By contrast, only the equations developed by Anandaraja, Hatori \& de Cordova et al, $[2,4,7]$ yielded values that correlated nonsignificantly with the measured values; in other words, these equations yielded near-actual values. However, the formula developed by Ahmadi et al. correlated most strongly with atherogenic dyslipidemia, nephropathy, and insulin resistance in our Pakistani cohort.

\section{Declarations}

Ethical approval: The study "Degree of concordance between calculated and measured low-density lipoprotein cholesterol methods" was formally approved by hospital's ethical review committee. We confirm that our research work conforms to “World Medical Association's Declaration of Helsinki - Ethical Principles for Medical Research Involving Human Subjects"

Signing of inform consent by participants: All subjects were required to sign written informed consent before participation into study. All included subjects were explained about the research requirements and use of data along with confidentiality issues.

Availability of SPSS data \& outputs: Subject data can be provided on formal request.

Author's contributions: SHK: (Corresponding Author) Idea conception, Diagnostic lab work, Manuscript writing. FS: Analysis of data, manuscript writing. RS: Patient selection, 
History and examination, data analysis and manuscript writing. SORSB: Statistical methods application, manuscript writing. SMM Lab work, data output (SPSS) analysis, contribution to writing manuscript. RA: data output (SPSS) analysis, contribution to writing manuscript, MT: Overall study coordination, medical writing. All study authors approved the final manuscript version.

\section{Acknowledgements}

The authors acknowledge assistance from Lab technician Ibrahim and Iftikhar.

\section{References}

1. Friedewald WT, Levy RI, Fredrickson DS (1972) Estimation of the concentration of low-density lipoprotein cholesterol in plasma, without use of the preparative ultracentrifuge. Clin Chem 18(6): 499502.

2. Anandaraja S, Narang R, Godeswar R, Laksmy R, Talwar KK (2005) Low-density lipoprotein cholesterol estimation by a new formula in Indian population. Int J Cardiol 102(1): 117-120.

3. Martin SS, Blaha MJ, Elshazly MB, Toth PP, Kwiterovich PO, et al (2013) Comparison of a novel method vs the Friedewald equation for estimating low-density lipoprotein cholesterol levels from the standard lipid profile. JAMA 310(19): 2061-2068.

4. Hattori Y, Suzuki M, Tsushima M, Yoshida M, Tokunaga Y, et al. (1998) Development of approximate formula for LDL-chol, LDL-apo B and LDL-chol/LDL-apo B as indices of hyperapobetalipoproteinemia and small dense LDL. Atherosclerosis 138(2): 289-299.

5. Chen Y, Zhang X, Pan B, Jin X, Yao H, et al. (2010) A modified formula for calculating low-density lipoprotein cholesterol values. Lipids Health Dis 9: 52 .

6. Vujovic A, Kotur-Stevuljevic J, Spasic S, Bujisic N, Martinovic J, et al. (2010) Evaluation of different formulas for LDL-C calculation. Lipids Health Dis 9: 27.

7. de Cordova CM, de Cordova MM (2013) A new accurate, simple formula for LDL-cholesterol estimation based on directly measured blood lipids from a large cohort. Ann Clin Biochem 50(Pt 1): 13-19.

8. Ahmadi SA, Boroumand MA, Gohari-Moghaddam K, Tajik P, Dibaj SM (2008) The impact of low serum triglyceride on LDL-cholesterol estimation. Arch Iran Med 11(3): 318-321.

9. Puavilai W, Laorugpongse D, Deerochanawong C, Muthapongthavorn N, Srilert P (2009) The accuracy in using modified Friedewald equation to calculate LDL from non-fast triglyceride: a pilot study. J Med Assoc Thai 92(2): 182-187.

10. Bayer P, Veinberg F, Couderc R, Cherfils C, Cambillau M, et al. (2005) Multicenter evaluation of four homogenous LDL-cholesterol assays. Ann Biol Clin (Paris) 63(1): 27-41.

11. Miida T, Nishimura K, Hirayama S, Miyamoto Y, Nakamura M, et al. (2017) Homogeneous Assays for LDL-C and HDL-C are Reliable in Both the Postprandial and Fasting State. J Atheroscler Thromb 24(6): 583599 .

12. Agrawal M, Spencer HJ, Faas FH (2010) Method of LDL cholesterol measurement influences classification of LDL cholesterol treatment goals: clinical research study. J Investig Med 58(8): 945-949.
13. Sugiuchi H, Manabe M, Irie T, Nagata S, Ando Y, et al. (2005) Pitfalls in homogeneous assays for HDL-c and LDL-c in serum. Rinsho Byori 53(2): 138-143.

14. NCEP (1994) National Cholesterol Education Program. Second report of the expert panel on detection, evaluation and treatment of high blood cholesterol in adults (Adult Treatment Panel II). Circulation 89(3): 1329-1345.

15. Wilcox HG, Davis DC, Heimberg M (1971) The isolation of lipoproteins from human plasma by ultracentrifugation in zonal rotors. J Lipid Res 2(2): $160-172$.

16. Toth PP (2014) Insulin resistance, small LDL particles, and risk for atherosclerotic disease. Curr Vasc Pharmacol 12(4): 653-657.

17. Matthews DR, Hosker JP, Rudenski AS, Naylor BA, Treacher DF, et al. (1985) Homeostasis model assessment: insulin resistance and betacell function from fasting plasma glucose and insulin concentrations in man. Diabetologia 28(7): 412-419.

18. Srisawasdi P, Chaloeysup S, Teerajetgul Y, Pocathikorn A, Sukasem C, et al. (2011) Estimation of plasma small dense LDL cholesterol from classic lipid measures. Am J Clin Pathol 136(1): 20-29.

19. Ide K, Koshizaka M, Tokuyama H, Tokuyama T, Ishikawa T, et al. (2018) N-3 polyunsaturated fatty acids improve lipoprotein particle size and concentration in Japanese patients with type 2 diabetes and hypertriglyceridemia: a pilot study. Lipids Health Dis 17(1): 51.

20. Nesto RW (2005) Beyond low-density lipoprotein: addressing the atherogenic lipid triad in type 2 diabetes mellitus and the metabolic syndrome. Am J Cardiovasc Drugs 5(6): 379-387.

21. Zhao X, Sun D, Xu RX, Guo YL, Zhu CG, et al. (2018) Low-density lipoprotein-associated variables and the severity of coronary artery disease: an untreated Chinese cohort study. Biomarkers 23(7): 647653.

22. Gerber PA, Nikolic D, Rizzo M (2017) Small, dense LDL: an update. Curr Opin Cardiol 32(4): 454-459.

23. Bilen 0, Kamal A, Virani SS (2016) Lipoprotein abnormalities in South Asians and its association with cardiovascular disease: Current state and future directions. World J Cardiol 8(3): 247-257.

24. Goel PK, Ashfaq F, Khanna R, Ramesh V, Pandey CM (2017) The Association Between Small Dense Low Density Lipoprotein and Coronary Artery Disease in North Indian Patients. Indian J Clin Biochem 32(2): 186-192.

25. Lepedda AJ, Nieddu G, Zinellu E, De Muro P, Piredda F, et al. (2013) Proteomic analysis of plasma-purified VLDL, LDL, and HDL fractions from atherosclerotic patients undergoing carotid endarterectomy: identification of serum amyloid A as a potential marker. Oxid Med Cell Longev 2013: 385214.

26. Havel RJ, Shames DM (1991) Kinetic studies of the origin of apolipoprotein (apo) B-100 in low density lipoproteins of normal and Watanabe heritable hyperlipidemic (WHHL) rabbits. Adv Exp Med Biol 285: $245-255$

27. Collins LA, Olivier M (2010) Quantitative comparison of lipoprotein fractions derived from human plasma and serum by liquid chromatography-tandem mass spectrometry. Proteome Sci 8: 42.

28. Toth PP (2017) Impact of lipoprotein remnants on 12-year risk for CHD in the framingham offspring population. Journal of the American College of Cardiology 61(10). 

(C) (-) This work is licensed under Creative

BY DOI: 10.19080/CRDOJ.2020.13.5566
Your next submission with Juniper Publishers will reach you the below assets

- Quality Editorial service

- Swift Peer Review

- Reprints availability

- E-prints Service

- Manuscript Podcast for convenient understanding

- Global attainment for your research

- Manuscript accessibility in different formats

( Pdf, E-pub, Full Text, Audio)

- Unceasing customer service

Track the below URL for one-step submission https://juniperpublishers.com/online-submission.php 